\title{
Pretest expectations strongly influence interpretation of abnormal laboratory results and further management
}

\author{
Paul HH Houben ${ }^{1 *}$, Trudy van der Weijden', Bjorn Winkens ${ }^{2}$, Ron AG Winkens ${ }^{1,3}$, Richard PTM Grol ${ }^{1,4}$
}

\begin{abstract}
Background: Abnormal results of diagnostic laboratory tests can be difficult to interpret when disease probability is very low. Although most physicians generally do not use Bayesian calculations to interpret abnormal results, their estimates of pretest disease probability and reasons for ordering diagnostic tests may - in a more implicit manner influence test interpretation and further management. A better understanding of this influence may help to improve test interpretation and management. Therefore, the objective of this study was to examine the influence of physicians' pretest disease probability estimates, and their reasons for ordering diagnostic tests, on test result interpretation, posttest probability estimates and further management.

Methods: Prospective study among 87 primary care physicians in the Netherlands who each ordered laboratory tests for 25 patients. They recorded their reasons for ordering the tests (to exclude or confirm disease or to reassure patients) and their pretest disease probability estimates. Upon receiving the results they recorded how they interpreted the tests, their posttest probability estimates and further management. Logistic regression was used to analyse whether the pretest probability and the reasons for ordering tests influenced the interpretation, the posttest probability estimates and the decisions on further management.

Results: The physicians ordered tests for diagnostic purposes for 1253 patients; 742 patients had an abnormal result (64\%). Physicians' pretest probability estimates and their reasons for ordering diagnostic tests influenced test interpretation, posttest probability estimates and further management. Abnormal results of tests ordered for reasons of reassurance were significantly more likely to be interpreted as normal (65.8\%) compared to tests ordered to confirm a diagnosis or exclude a disease $(27.7 \%$ and $50.9 \%$, respectively). The odds for abnormal results to be interpreted as normal were much lower when the physician estimated a high pretest disease probability, compared to a low pretest probability estimate $(\mathrm{OR}=0.18,95 \% \mathrm{Cl}=0.07-0.52, \mathrm{p}<0.001)$.

Conclusions: Interpretation and management of abnormal test results were strongly influenced by physicians' estimation of pretest disease probability and by the reason for ordering the test. By relating abnormal laboratory results to their pretest expectations, physicians may seek a balance between over- and under-reacting to laboratory test results.
\end{abstract}

\section{Background}

Laboratory tests are frequently ordered in routine primary care as part of the diagnostic process, even though the physician's pretest expectation may often be that the probability of disease is low, and they often order tests for other than purely medical reasons, such as patient

\footnotetext{
* Correspondence: paul.houben@hag.unimaas.nl

${ }^{1}$ Maastricht University, School of Public Health and Primary Care (CAPHRI), Department of General Practice, PO Box 616, 6200 MD Maastricht, the Netherlands
}

(c) 2010 Houben et al; licensee BioMed Central Ltd. This is an Open Access article distributed under the terms of the Creative Commons Attribution License (http://creativecommons.org/licenses/by/2.0), which permits unrestricted use, distribution, and reproduction in any medium, provided the original work is properly cited. reassurance $[1,2]$. As a consequence of the statistical definitions used for the reference values for laboratory tests, abnormal results are frequent, even in healthy individuals [3]. For example, in a screening programme with healthy individuals, a battery of 8 blood chemistry tests yielded at least one abnormal result for $20.6 \%$ of the individuals [4]. Abnormal results may therefore be difficult to interpret, certainly in the light of the low probability of serious disease in the primary care population [5]. 
When physicians interpret test results and make plans for further management, it would be interesting to know to what extent they take their pretest expectations into account. For example, many physicians have difficulty performing Bayesian calculations to interpret test results, as such calculations may be complex and are often not easily applicable to situations where several diagnostic hypotheses are considered and several tests are ordered [6]. However, physicians' pretest expectations, such as their estimates of pretest probability and their reasons for ordering diagnostic tests (for example to exclude or confirm disease or to reassure patients) may influence test result interpretation and management, though perhaps not in a direct Bayesian fashion but probably in a more implicit way. Although the influence of physicians' pretest expectations on the ordering of tests has been extensively studied, little is known about the influence of their pretest expectations on the interpretation of test results and further management in routine care, as research on this subject has been scarce $[7,8]$. A better understanding of this influence may help to improve test interpretation and management. The objective of this study was therefore to examine the influence of physicians' pretest expectations in terms of estimated pretest disease probability, and their reasons for ordering diagnostic tests, on the subsequent interpretation of the results of these diagnostic tests and further management.

\section{Methods}

\section{Design and Setting}

We conducted a prospective study among primary care physicians and their patients in 7 rural, suburban and urban areas in the south of the Netherlands, in 2004/05. Each participating physician was instructed to record data on 25 adult patients for whom they had decided to order laboratory tests during the consultation. To prevent selection bias, they were instructed to include the first 25 patients for whom laboratory tests were ordered, without any further selection. Physicians working parttime included a smaller number of patients, proportional to the number of hours a week they worked. Patients were asked to give informed consent. The Maastricht Medical Ethics Committee approved the study (reference number MEC 03-195-1).

\section{Measurements}

The physicians recorded data both when they ordered the laboratory tests and when they received the test results, using forms that were specifically designed for the study and took about 2 minutes to complete [additional file 1] [additional file 2]. The forms had been pilot-tested and evaluated as regards validity, reliability and user convenience in an iterative process among a sample of ten primary care physicians and a questionnaire expert.

\section{Variables, pretest expectations \\ Reason for ordering tests}

We distinguished nine reasons for test ordering, which were chosen on the basis of a qualitative interview study among primary care physicians about ordering and interpreting laboratory tests [9]. Physicians recorded the most important reason for ordering the investigations by ticking one of nine check-off boxes. We summarized these into five categories: (1) to exclude disease and reduce the physician's own uncertainty, (2) to confirm diagnosis and to determine treatment, (3) to reassure patients and at patients' request, (4) to screen for hypertension/cholesterol/diabetes and check-up for a known disorder and (5) other reasons.

\section{Pretest estimate of disease probability}

The form that the physicians had to complete asked: 'Do you suspect that the patient has a disease?'. The physicians answered on a 5-point Likert scale: 'definitely not', 'probably not', 'maybe', 'probably yes' and 'definitely yes'.

\section{Variables, outcomes}

\section{Interpretation of the laboratory results}

When the physicians received the results we asked them: 'How do you interpret these results for this patient?' The physicians answered on a 3-point scale; 'normal', 'possibly abnormal' or 'clearly abnormal'.

\section{Posttest estimate of disease probability}

The form that the physicians had to complete asked: 'Do you suspect that the patient has a disease?'. The physicians answered on a 5-point Likert scale: 'definitely not', 'probably not', 'maybe', 'probably yes' and 'definitely yes'.

\section{Management}

We distinguished nine management items, and physicians were instructed to select one or two items in check-off boxes. We classified these items into passive and active management items. Passive management items were 'reassurance/explanation', 'expectative/waitand-see', 'advice (about lifestyle, complaints, etc.)', and 'instructions'. Active management items were 'additional investigations (laboratory, imaging, etc.)', 'new/follow-up appointment', 'medication (start, stop, change)', referral (specialist, other health care provider) and 'other management'. We defined the management as active if at least one of the checked boxes was an active management item.

\section{Analysis}

Only patients for whom the physician ordered laboratory tests for diagnostic purposes (reasons 1-3) were included in the analysis. We excluded patients for whom tests were ordered for screening, check-up or 
other reasons. We included all test results reported by the regional laboratories and defined a patient's results as abnormal if at least one test was outside the laboratories' reference values. We used chi-square tests to identify significant differences in interpretation, posttest probability estimates and management between the various reasons for ordering tests and between the various estimates of pretest probability.

Three logistic regression models were applied to the data. The first model analysed the influence of patients' age and sex, the reason for ordering tests and the pretest probability on the interpretation of the results. The second model incorporated the previous variables, plus the interpretation of the results, as independent variables, and analysed their influence on the posttest probability estimates. Finally, the third model investigated the influence of all previous variables on the management. To be able to apply logistic regression, we dichotomized the dependent variables, distinguishing the categories 'normal' and 'possibly or clearly abnormal' for the interpretation of results, and the categories 'low probability' (definitely not/probably not) and 'high probability' (maybe/probably yes/definitely yes) for the posttest probability. We considered P-values smaller than or equal to 0.05 to be significant. We checked for multicollinearity (condition index $>30$ and variance decomposition proportion (VDP) $>0.5$ ) and tested the goodnessof-fit using the Hosmer and Lemeshow test. Also, to check whether the responses obtained for the individual patients were correlated within doctors, we performed a generalized estimating equations (GEE) analysis with an exchangeable working correlation structure. All analyses were performed with SPSS version 16.0.

\section{Results}

Eighty-seven primary care physicians participated, and together they included 1775 patients (table 1). Laboratory tests were ordered for diagnostic reasons for 1253 (71\%) patients. We received no laboratory results for $7.2 \%$ of these patients, the primary reason being that patients failed to visit the laboratory (29\%). The laboratories reported 11,548 tests for the remaining 1,163 patients, a mean of 9.9 tests per patient. The most common reason for ordering tests was to exclude disease (62\%). Tests for reassurance were ordered for $20 \%$ of the patients. The estimated pretest disease probability was low for $43 \%$ of the patients (table 2). There were 742 patients (64\%) with a laboratory result including one or more abnormal tests.

The physicians interpreted the abnormal laboratory results for these 742 patients as normal in $48 \%$ of the cases, while their estimation of the posttest probability was low in $49.5 \%$ of the cases, and their management consisted of 'no action' for $49.2 \%$ of these patients. The
Table 1 Characteristics of primary care physicians and patients

\begin{tabular}{ll}
\hline Primary care physicians & $\mathbf{N}=\mathbf{8 7}$ (NIVEL*) \\
\hline Sex & \\
man & $68 \%(67 \%)$ \\
woman & $32 \%(33 \%)$ \\
Age & \\
$\quad<50$ years & $68 \%(55 \%)$ \\
$\quad>50$ years & $32 \%(45 \%)$ \\
Experience ** & \\
$\quad<15$ years & \\
$>15$ years & $41 \%$ \\
Working & $59 \%$ \\
$\quad$ full-time & \\
part-time & $52 \%(54 \%)$ \\
Patients & $48 \%(46 \%)$ \\
Sex $\quad \mathrm{N}=1253$ \\
$\quad$ man \\
woman \\
Age \\
18-40 years \\
$40-60$ years \\
$60+$ years
\end{tabular}

* the Netherlands Institute for Health Services Research http://www.nivel.nl documents data on all Dutch primary care physicians $(\mathrm{N}=8408$, data 2005). ** No Nivel data available

percentage of patients whose abnormal results were interpreted as normal was significantly larger if tests were ordered to reassure $(65.8 \%)$ compared with other reasons $(50.9 \%$ and $27.7 \%, \mathrm{p}<0.001)$ and was significantly larger if the pretest probability was estimated to be low (66.1\%) compared with high pretest probabilities $(19.6 \%, \mathrm{p}<0.001)$. Similar significant relations were found for the posttest probability estimates and the management (table 3). If tests were ordered for reassurance or if the physicians' pretest probability estimate was low, the interpretation for patients (comparable in terms of age and sex) having only normal results was 'normal' in $100 \%$ of the cases. The posttest probability

Table 2 Reasons for ordering laboratory tests and pretest probability estimates

\begin{tabular}{lr}
\hline Reason for ordering lab tests & $N=1147$ (16 missing) \\
reassure patient & $226(20 \%)$ \\
exclude disease & $708(62 \%)$ \\
confirm diagnosis & $213(19 \%)$ \\
Estimate of pretest disease probability & $N=1138(25$ missing) \\
definitely no disease & $114(10 \%)$ \\
probably no disease & $377(33 \%)$ \\
maybe & $329(29 \%)$ \\
probably disease & $252(22 \%)$ \\
definitely disease & $66(6 \%)$ \\
\hline
\end{tabular}


Table 3 Interpretation, posttest disease probability estimates and management after receiving abnormal laboratory results.

\begin{tabular}{|c|c|c|c|}
\hline & $\begin{array}{r}\text { Test interpretation } \\
=\text { normal }\end{array}$ & $\begin{array}{r}\text { Posttest probability } \\
=\text { no disease }\end{array}$ & $\begin{array}{l}\text { Management } \\
=\text { no action }\end{array}$ \\
\hline \multicolumn{4}{|l|}{ Reason for ordering lab tests } \\
\hline reassure patient & $75(65.8 \%)^{*}$ & $90(76.9 \%)^{*}$ & $85(75.2 \%)^{*}$ \\
\hline exclude disease & $220(50.9 \%)$ & $224(51.1 \%)$ & $214(49.4 \%)$ \\
\hline confirm diagnosis & $41(27.7 \%)$ & $34(23.0 \%)$ & $43(28.9 \%)$ \\
\hline \multicolumn{4}{|l|}{ Pretest probability estimate } \\
\hline definitely no disease & $37(66.1 \%)^{*}$ & $48(84.2 \%)^{*}$ & $42(76.4 \%)^{*}$ \\
\hline probably no disease & $139(67.1 \%)$ & $150(71.8 \%)$ & $137(66.8 \%)$ \\
\hline maybe & $95(45.2 \%)$ & $101(47.6 \%)$ & $91(43.1 \%)$ \\
\hline probably disease & $55(31.4 \%)$ & $43(24.0 \%)$ & $58(32.8 \%)$ \\
\hline definitely disease & 9 (19.6\%) & $6(13.0 \%)$ & $14(29.8 \%)$ \\
\hline
\end{tabular}

${ }^{*}$ Chi-square test, $\mathrm{p}<0.001$

estimates were low in $100 \%$ and $96.6 \%$ of the cases, respectively, while the management was 'no action' in $88.9 \%$ and $91.2 \%$ of the patients, respectively.

If tests were ordered for reassurance, the percentage of patients with abnormal results being offered further diagnostic investigations was $8.8 \%$, while none of the patients whose laboratory results were normal were offered further investigations. Of the patients with a low pretest probability and abnormal results, $11.1 \%$ were offered further investigations by their physician, while $3.7 \%$ of the patients with a low pretest probability and normal results were offered further investigations.

Table 4 shows the results of the logistic regression analysis. There was no multicollinearity. Compared to a low pretest probability estimate, a high estimate decreased the likelihood that abnormal results were interpreted as normal $(\mathrm{OR}=0.18,95 \% \mathrm{CI}=0.07-0.52$, $\mathrm{p}$ $<0.001$ ) and also decreased the likelihood of a low posttest probability estimate $(\mathrm{OR}=0.04,95 \% \mathrm{CI}=0.01$ $0.23, \mathrm{p}<0.001)$. The physicians were also less likely to interpret abnormal tests as normal if the laboratory tests were ordered to confirm a diagnosis, compared to those ordered to exclude disease (OR 0.59, CI 0.37-0.93, p = 0.067). The likelihood of passive management ('no action') increased if tests were ordered for reassurance, compared to those ordered to exclude disease (OR 2.25, CI 1.08-4.66, $\mathrm{p}=0.06$ ).

The intraclass correlations calculated by the generalized estimating equations analysis were small. For the three models they were $0.022,0.050$ and 0.015 respectively. There were similar results for the significance of the variables and the odds ratios as compared to the results from the logistic regression analysis.

\section{Discussion}

The results show that the interpretation of test results, posttest disease probability estimates and management were significantly influenced by the physicians' pretest expectations. If the pretest probability was low or when tests were ordered at patients' request or to reassure them, the physicians tended to interpret abnormal results as normal and not to initiate further action. On the whole, this may be a correct decision, since many laboratory abnormalities will not be clinically relevant if the pretest probability is low. Physicians may use their pretest expectations to seek a balance between overand under-reacting to laboratory test results.

To our knowledge, research about physicians' routine interpretation of laboratory results is still scarce. This study attempted to examine what they do with the results of laboratory tests. Strong points of this study were that it included many physicians and patients, that the data were prospectively collected and that we tried to prevent selection bias by instructing the physicians to include consecutive patients for whom laboratory tests were ordered.

A disadvantage of our method was the heterogeneity in terms of laboratory tests, abnormal results and diagnoses. This means that interpretation and management cannot be related to a specific test, abnormality or diagnosis. In the context of this study, however, it would have been unrealistic to reduce clinical variation to a minimum and thus force the physicians into a standardized study, since the primary goal was to examine whether pretest expectations influence interpretation, posttest probability estimates and management in dayto-day care. It could be interesting in future studies to examine in more detail how specific tests influence further diagnosis and management. Another limitation is that the abnormal results in the group of patients with a low pretest probability may have been less abnormal than those for patients with a high pretest probability. Such differences in the level of abnormality of test results may have influenced physicians' interpretation of 
Table 4 Influence of pretest expectations on interpretation, posttest probability estimates and management after abnormal results.

\begin{tabular}{|c|c|c|c|}
\hline & $\begin{array}{r}\text { Test interpretation } \\
=\text { normal }^{+} \\
\text {odds ratio }(95 \% \mathrm{Cl})\end{array}$ & $\begin{array}{l}\text { Posttest probability } \\
=\text { no disease } \\
\text { f } \\
\text { odds ratio }(95 \% \mathrm{Cl})\end{array}$ & $\begin{array}{r}\text { Management } \\
=\text { no action } \\
\S\end{array}$ \\
\hline Reason for ordering lab tests & $p=0.067$ & $p=0.52$ & $p=0.06$ \\
\hline exclude disease & 1 & 1 & 1 \\
\hline reassure patient & $1.1(0.63-1.83)$ & $1.46(0.67-3.17)$ & $2.25(1.08-4.66)$ \\
\hline confirm diagnosis & $0.59(0.37-0.93)$ & $0.82(0.42-1.59)$ & $0.80(0.46-1.40)$ \\
\hline Pretest probability estimate & $p<0.001$ & $p<0.001$ & $p=0.19$ \\
\hline definitely no disease & 1 & 1 & 1 \\
\hline probably no disease & $1.13(0.56-2.26)$ & $0.35(0.11-1.08)$ & $1.67(0.64-4.32)$ \\
\hline maybe & $0.49(0.24-1.03)$ & $0.20(0.06-0.63)$ & $1.11(0.41-3.00)$ \\
\hline probably disease & $0.33(0.15-0.73)$ & $0.07(0.02-0.23)$ & $1.75(0.59-5.17)$ \\
\hline definitely disease & $0.18(0.07-0.52)$ & $0.04(0.01-0.23)$ & $2.88(0.79-10.59)$ \\
\hline Test interpretation & $N / A^{*}$ & $p<0.001$ & $p<0.001$ \\
\hline normal & & 1 & 1 \\
\hline possibly abnormal & & $0.09(0.06-0.15)$ & $0.20(0.10-0.40)$ \\
\hline abnormal & & $0.01(0.005-0.02)$ & $0.43(0.25-0.72)$ \\
\hline Posttest probability estimate & $N / A^{*}$ & $N / A^{*}$ & $p<0.001$ \\
\hline definitely no disease & & & 1 \\
\hline probably no disease & & & $0.48(0.26-0.89)$ \\
\hline maybe & & & $0.14(0.07-0.32)$ \\
\hline probably disease & & & $0.07(0.03-0.16)$ \\
\hline definitely disease & & & $0.09(0.04-0.23)$ \\
\hline
\end{tabular}

the test results and their further management. This influence was difficult to correct for in our analyses, as many different laboratory tests were ordered. Future studies may address more specifically the influence of the level of abnormality of test results on interpretation and further management.

Finally, as each physician included several patients, there may have been a certain clustering of specific interpretations and behaviour at the level of the physician. We have not analyzed this, as the focus of the study was to explore how pretest expectations influence the interpretation of results at the level of individual patients, and we did not intend to explore the differences in interpretation between physicians. We recruited a large group of practitioners (87) to ensure external generalizability of our findings.

Our study found that the pretest disease probability strongly influenced the physicians' interpretation of the laboratory results and their posttest probability estimates. This seems in line with Bayesian theory, which shows that the significance of a particular test result depends on pretest probability [10]. But it has also been pointed out that physicians are often not very proficient at the calculations that this theory requires, and they do not routinely use these calculations $[6,11]$. There may be a gap between physicians' performance in terms of these calculations and the way they interpret laboratory results in routine care. This discrepancy might be addressed in future research.

Furthermore, the magnitude of abnormality of a test may be an important factor in the interpretation of results. When test results are dichotomized into normal and abnormal, important information may be lost. It may therefore be useful not to dichotomize test results, but to use, for example, likelihood ratios instead. These likelihood ratios may help physicians come to a more appropriate interpretation of test results [12], although it remains unclear if they are really helpful in routine practice $[13,14]$.

Since many of the abnormal laboratory results hardly affected posttest probability estimates and management in our study, physicians should carefully consider if it was useful to order the tests in the first place. Also, the physicians ordered further investigations for nearly $10 \%$ of the patients for whom the original tests had been ordered for reassurance. It may be doubted if this was necessary, since it has been shown that investigations may also have negative consequences, such as an unjustified cascade of further investigations to explain unexpected abnormalities $[15,16]$. In view of the number of 
patients in this study who were offered further investigations, future research should examine how often negative consequences of laboratory testing, such as cascade processes, occur.

\section{Conclusions}

Physicians' interpretation of laboratory results and further management after receiving the results of laboratory tests is clearly influenced by their pretest expectations. Physicians may use these expectations to seek a balance between over- and under-reacting to laboratory results. Our findings help to understand interpretation and use of laboratory results in day-to-day care. However, further research into the interpretation and use of laboratory results, including different levels of abnormality, is necessary and might in the future help to improve test interpretation and management.

Additional file 1: Questionnaire 1. Questionnaire used for data

recording when the physicians ordered the laboratory tests.

Click here for file

[http://www.biomedcentral.com/content/supplementary/1471-2296-11-

13-S1.DOC ]

Additional file 2: Questionnaire 2. Questionnaire used for data

recording when the physicians received the test results.

Click here for file

[http://www.biomedcentral.com/content/supplementary/1471-2296-1113-S2.DOC ]

\section{Acknowledgements}

We are most grateful to the physicians and clinical laboratories that supported the data collection for this study.

\section{Author details}

'Maastricht University, School of Public Health and Primary Care (CAPHRI), Department of General Practice, PO Box 616, 6200 MD Maastricht, the Netherlands. ${ }^{2}$ Maastricht University, School of Public Health and Primary Care (CAPHRI), Department of Methodology and Statistics, PO Box 616, 6200 MD Maastricht, the Netherlands. ${ }^{3}$ Maastricht University Medical Centre, Integrated Care Unit, PO Box 5800, 6202 AZ Maastricht, the Netherlands. ${ }^{4}$ Radboud University Nijmegen, Scientific Institute for Quality of Healthcare, PO Box 9101, 6500 HB Nijmegen, the Netherlands.

\section{Authors' contributions}

PHH, TvdW, RAGW and RPTMG designed the study. PHH, TvdW, RAGW participated in the data collection. PHH and BW analysed the data. PHH drafted the manuscript. RPTMG, TvdW, RAGW and BW participated in writing the manuscript. RPTMG supervised all parts of this study. All authors read and approved the final manuscript

\section{Competing interests}

The authors declare that they have no competing interests.

Received: 31 March 2009

Accepted: 16 February 2010 Published: 16 February 2010

\section{References}

1. Leurquin P, Van Casteren V, De Maeseneer J: Use of blood tests in general practice: a collaborative study in eight European countries. Eurosentinel Study Group. Br J Gen Pract 1995, 45(390):21-25.
2. Weijden van der T, van Bokhoven MA, Dinant GJ, van Hasselt CM, Grol RP: Understanding laboratory testing in diagnostic uncertainty: a qualitative study in general practice. Br J Gen Pract 2002, 52(485):974-980.

3. Phillips WR, Thompson DJ: Multi-channel laboratory testing and the unexpected abnormal result: a statistical myth corrected. N Z Med 1981, 94(698):462-464.

4. Mold JW, Aspy CB, Lawler FH: Outcomes of an insurance companysponsored multichannel chemistry screening initiative. J Fam Pract 1998, 47(2):110-117.

5. Brigden ML, Heathcote JC: Problems in interpreting laboratory tests. What do unexpected results mean?. Postgrad Med 2000, 107(7):145-146.

6. Reid MC, Lane DA, Feinstein AR: Academic calculations versus clinical judgments: practicing physicians' use of quantitative measures of test accuracy. Am J Med 1998, 104(4):374-380.

7. Verstappen WH, ter Riet G, Dubois WI, Winkens R, Grol RP, Weijden van der $\mathrm{T}$ : Variation in test ordering behaviour of GPs: professional or contextrelated factors?. Fam Pract 2004, 21(4):387-395.

8. Holtgrave DR, Lawler F, Spann SJ: Physicians' risk attitudes, laboratory usage, and referral decisions: the case of an academic family practice center. Med Decis Making 1991, 11(2):125-130.

9. Houben PHH, Weijden van der T, van Bokhoven MA, Droog A, Winkens RA, Grol R: Overwegingen van huisartsen bij het interpreteren van laboratoriumonderzoek; een kwalitatief onderzoek. Huisarts Wet 2005, 48(7):736-732.

10. Gigerenzer $\mathrm{G}$, Hoffrage $\mathrm{U}$ : How to improve bayesian reasoning without instruction: frequency formats. Psychol Rev 1995, 102(4):684-704.

11. Steurer J, Fischer JE, Bachmann LM, Koller M, ter Riet G: Communicating accuracy of tests to general practitioners: a controlled study. BMJ 2002, 324(7341):824-826.

12. Brown MD, Reeves MJ: Evidence-based emergency medicine/skills for evidence-based emergency. Ann Emerg Med 2003, 42(2):292-7.

13. Puhan MA, Steurer J, Bachmann LM, ter Riet G: A randomized trial of ways to describe test accuracy: the effect on physicians' post-test probability estimates. Ann Intern Med 2005, 143(3):184-189.

14. Sonis J: How to use and interpret interval likelihood ratios. Fam Med 1999, 31(6):432-7.

15. Deyo RA: Cascade effects of medical technology. Annu Rev Public Health 2002, 23:23-44

16. Vafiadis P: The dilemma of the unexpected result. Aust Fam Physician 1996, 25(6):971-973.

Pre-publication history

The pre-publication history for this paper can be accessed here:http://www biomedcentral.com/1471-2296/11/13/prepub

doi:10.1186/1471-2296-11-13

Cite this article as: Houben et al.: Pretest expectations strongly influence interpretation of abnormal laboratory results and further management. BMC Family Practice 2010 11:13.

\section{Submit your next manuscript to BioMed Central and take full advantage of:}

- Convenient online submission

- Thorough peer review

- No space constraints or color figure charges

- Immediate publication on acceptance

- Inclusion in PubMed, CAS, Scopus and Google Scholar

- Research which is freely available for redistribution

Submit your manuscript at www.biomedcentral.com/submit
C Biomed Central 